\title{
Photodegradation of Methylene Blue in $\mathrm{Fe}_{2} \mathrm{O}_{3}-\mathrm{Oxalate}$ Suspension Under UV Light Irradiation
}

\author{
A. Z. M. Mainul Islam Mazumder ${ }^{1, ~ *, ~ M d . ~ S o f i u l ~ A l o m ², ~ T a j m e r i ~ S . ~ A . ~ I s l a m ~}{ }^{1}$ \\ ${ }^{1}$ Department of Chemistry, Faculty of Science, University of Dhaka, Dhaka, Bangladesh \\ ${ }^{2}$ Department of Chemistry, Faculty of Engineering, Dhaka University of Engineering \& Technology, Gazipur, Bangladesh \\ Email address: \\ mainulmazumder@du.ac.bd (A. Z. M. I. Mazumder), sofiul@duet.ac.bd (Md. S. Alom), tajmeri@du.ac.bd (T. S. A. Islam) \\ ${ }^{*}$ Corresponding author
}

\section{To cite this article:}

A. Z. M. Mainul Islam Mazumder, Md. Sofiul Alom, Tajmeri S. A. Islam. Photodegradation of Methylene Blue in $\mathrm{Fe}_{2} \mathrm{O}_{3}-\mathrm{Oxalate}_{\mathrm{Suspension}}$ Under UV Light Irradiation. American Journal of Physical Chemistry. Vol. 7, No. 1, 2018, pp. 6-11. doi: 10.11648/j.ajpc.20180701.12

Received: April 7, 2018; Accepted: April 23, 2018; Published: May 18, 2018

\begin{abstract}
The aim of this study was to investigate the photodegradation of organic pollutants in natural environment with co-existence of iron oxides and oxalic acid. Methylene Blue (MB) was selected as a model pollutant while $\mathrm{Fe}_{2} \mathrm{O}_{3}$ was selected as iron oxide. Commercial $\mathrm{Fe}_{2} \mathrm{O}_{3}$ was calcined at $300^{\circ} \mathrm{C}, 400^{\circ} \mathrm{C}$ and $500^{\circ} \mathrm{C}$ and was used to degrade $\mathrm{MB}$ in oxalate solutions of different concentration under UV radiation. Adsorption of $\mathrm{MB}$ on the surface of calcined $\mathrm{Fe}_{2} \mathrm{O}_{3}$ was studied and 30 minutes was required to reach the adsorption equilibrium. The effect of the initial concentration of oxalic acid, initial concentration of $\mathrm{MB}$ and calcined temperature of $\mathrm{Fe}_{2} \mathrm{O}_{3}$ on photodegradation of $\mathrm{MB}$ in the $\mathrm{Fe}_{2} \mathrm{O}_{3}$-oxalate suspension under $\mathrm{UV}$ light irradiation was investigated. Oxalic acid plays a very important role, no significant degradation of MB was found in absence of oxalic acid in the suspension. But excess concentration of oxalic acid decreases the degradation. Photodegradation of MB increases with increasing calcined temperature of $\mathrm{Fe}_{2} \mathrm{O}_{3}$ and decreases with increase in $\mathrm{MB}$ concentration. Since this process does not require the addition of hydrogen peroxide and shows good efficiency under UV irradiation, it is an economically viable method for pre-treating wastewater containing dye.
\end{abstract}

Keywords: Methylene Blue, Photodegradation, $\mathrm{Fe}_{2} \mathrm{O}_{3}-\mathrm{Oxalate}$ Suspension, Adsorption

\section{Introduction}

Industrial wastewater contains dyes and other organic pollutants. The increasing diversity of manufactured products increases the complexity of wastewater particularly the dye house wastewater. Dye house wastewater usually contains about $10-50 \mathrm{mg} / \mathrm{L}$ of dyes [1] which is high enough concentration to induce a remarkable coloring of the receiving water bodies where they are discharged. Methylene Blue is very common among many azo dyes used in textile industries. Methylene blue [3,9-bis dimethyl-aminophenazothionium chloride] is a cationic dye containing a heterocyclic aromatic ring. It is a well-known animal mutagen and highly toxic through oral and intravenous routes. Dryness of mouth, flushed skin, rapid pulse, blurred vision, dizziness etc. could be the consequences of inhalation of methylene blue.

Colored effluents cannot be removed efficiently by conventional biological methods. In most of the biological methods dyes are absorbed onto biomass without being degraded [2] which is a kind of pollution transfer. But the sludge should be discarded in a sustainable manner. Recently, there has been considerable interest in the utilization of advanced oxidation processes (AOPs) to destroy organic compounds. AOPs are based on the production of hydroxyl radicals as oxidizing agents to mineralize organic chemicals. Besides ozonation [3] and fenton reaction [4] many efforts have been directed at the photodegradation of organic dyes by different UV irradiation systems in combination with $\mathrm{H}_{2} \mathrm{O}_{2}$ [5, 6], fenton [4, 5] or with photocatalyst. The photocatalytic degradation of azoic dyes in a $\mathrm{TiO}_{2}$ suspension has been investigated by several research groups [7-10] all over the world. The two main AOP methods to destroy organic pollutants are-(i) Oxidation in the presence of $\mathrm{H}_{2} \mathrm{O}_{2}$ and light, (ii) Semiconductor mediated photodegradation.

Different forms of iron oxides and hydroxides such as 
hematite $\left(\alpha-\mathrm{Fe}_{2} \mathrm{O}_{3}\right)$, maghemite, magnetite $\left(\mathrm{Fe}_{3} \mathrm{O}_{4}\right)$, geolite $(\alpha-\mathrm{FeOOH})$ etc show semiconductor properties due to their narrow band gaps $(2.0-2.3 \mathrm{eV})$. These oxides and hydroxides of iron should therefore be photoactive under solar radiation [11]. A photochemical system can be constructed by combining iron oxides and polycarboxylic acids to give a photo-fenton like reaction without the addition of $\mathrm{H}_{2} \mathrm{O}_{2}$ and with much higher quantum efficiency than with $\mathrm{Fe}(\mathrm{OH})^{2+}$ or iron oxides alone [12]. Both iron oxides and polycarboxylic acids are abundant in nature. Oxalic acid is an active polycarboxylic acids.

Iron is the fourth most abundant element of the earth's crust (5.1 mass \%). Iron oxides are kind of natural minerals and geocatalysts. Soils, lakes and rivers are major sources of iron oxides [13]. On the other hand, oxalic acid is discharged by plant roots in natural environment [14]. It can also be found as a byproduct of oil manufacturing $[15,16]$. Oxalic acid shows strong chelating ability with multivalent cations. Ligand-to-metal charge transfer ability of $\mathrm{Fe}^{3+}$-oxalate is very strong [17]. Hence, it can be expected that $\mathrm{Fe}^{3+}$-oxalate complexes could undergo photochemical reactions in surface soil and surface water. In the past decade, several studies had reported the photochemical process of Fe(III)-oxalate and iron oxide-oxalate systems for degradation of organic pollutants [18-23]. For iron oxide-oxalate suspension system, $\mathrm{Fe}(\mathrm{III})$-oxalate complexes includes dissolved ones and adsorbed ones [21, 22]. Fe(III)-oxalate complexes produces superoxides and hydroperoxyl radicals $\left(\mathrm{O}_{2}{ }^{-} / \mathrm{O}_{2} \mathrm{H}\right)$ when illuminated with UV and/or visible light [24].

\section{Experimental}

$\mathrm{Fe}_{2} \mathrm{O}_{3}$, obtained from Merck, Germany were calcined at three different temperatures $\left(300^{\circ} \mathrm{C}, 400^{\circ} \mathrm{C}\right.$ and $\left.500^{\circ} \mathrm{C}\right)$ to use as photocatalyst. Oxalic Acid was also obtained from Merck, Germany. All the aqueous solutions were prepared with deionized water. $1.0 \times 10^{-3} \mathrm{M}$ methylene blue (Dyester, Germany) solution was prepared in $100.0 \mathrm{~mL}$ volumetric flask. Required dilute solutions were prepared from this stock solution. The absorbance of each solution was measured at $\lambda_{\max }=664 \mathrm{~nm}$ using UV-visible spectrophotometer (UV1650PC, Shimadzu, Japan). The concentration range of MB used in this experiment was $0.5 \times 10^{-5} \mathrm{M}$ to $5 \times 10^{-5} \mathrm{M}$.

In case of photodegradation of $\mathrm{MB}$, the reaction mixture containing $\mathrm{MB}$, oxalic acid (OA) and $\mathrm{Fe}_{2} \mathrm{O}_{3}$ were kept in dark (with continuous stirring) for 30 minutes to reach the adsorption equilibrium and then the reaction mixture was irradiated with UV light. Aliquot portion of the reaction mixture was collected at different time intervals during irradiation. It was then centrifuged (Laboratory centrifuge machine-3000 cps, Heka, BHG) and analyzed using UVvisible spectrophotometer to determine the concentration of MB. The reactor in which experiments were carried out was a beaker of inside diameter of $4.3 \mathrm{~cm}$ and height of $5.5 \mathrm{~cm}$. The source of radiation was comprised of a lamp emitting monochromatic radiation of $254 \mathrm{~nm}$. The reactor was placed on a magnetically stirred plate and the distance of the solution surface from the lower part of the lamp was fixed at $5.0 \mathrm{~cm}$ by adjusting the plate height. The total system was enclosed in a wooden box called lamp house. Inside surfaces of the lamp house was covered by aluminium foil to avoid the absorption of light.

\section{Results and Discussion}

\subsection{Adsorption of $\mathrm{MB}$ on $\mathrm{Fe}_{2} \mathrm{O}_{3}$ Surface}

Adsorption is a prerequisite for photodegradation. MB molecules can be adsorbed on the $\mathrm{Fe}_{2} \mathrm{O}_{3}$ surface. To examine the adsorption of $\mathrm{MB}$ on $\mathrm{Fe}_{2} \mathrm{O}_{3}$ surface and to determine the time required to reach the adsorption equilibrium an experiment was performed by stirring MB solution in $0.5 \mathrm{~g} / \mathrm{L}$ of $\mathrm{Fe}_{2} \mathrm{O}_{3}$ suspension in absence of any light source. After 30 minutes adsorption attained equilibrium condition (Figure 1). Shiva et al. found that adsorption of the MB to magneticmodified $\mathrm{Fe}_{3} \mathrm{O}_{4}$ nanoparticles reached equilibrium after 25 min [25]. For photodegradation of $\mathrm{MB}$, reaction mixtures were kept in dark (with continuous stirring) for 30 minutes before it was exposed to the light source to allow the MB to be adsorbed on the $\mathrm{Fe}_{2} \mathrm{O}_{3}$ surface.

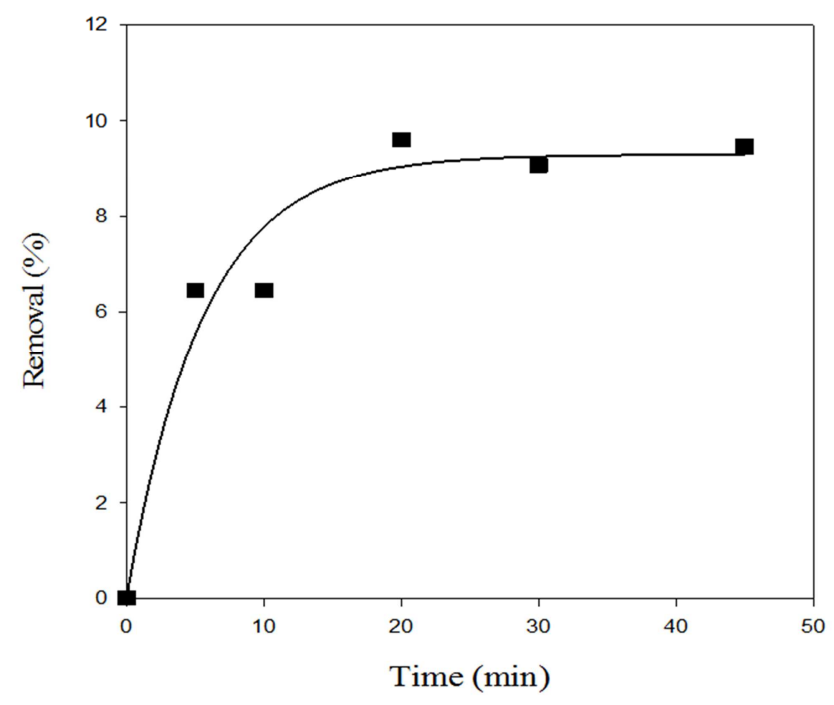

Figure 1. Percentage removal of $\mathrm{MB}$ by adsorption on $0.5 \mathrm{~g} / \mathrm{L} \mathrm{Fe}_{2} \mathrm{O}_{3}$; where, initial concentration of $M B=1.0 \times 10^{-5} \mathrm{M}$ and initial concentration of oxalic acid $=1.0 \times 10^{-3} \mathrm{M}$.

\subsection{Role of Oxalic Acid and UV-light on Photodegradation of $M B$}

Several experiments were performed to examine the role of oxalic acid and light source during photodegradation of MB under different experimental conditions. When MB was irradiated with UV light in a suspension that contains $0.5 \mathrm{~g} / \mathrm{L}$ $\mathrm{Fe}_{2} \mathrm{O}_{3}$, decrease in concentration of MB was very small. But presence of oxalic acid in $0.5 \mathrm{~g} / \mathrm{L}$ suspension increases the degradation of MB significantly. Again, almost no decrease in concentration of MB was occurred when the same system was kept in dark. This results support that the photodegradation of MB proceed by the formation of iron- 
oxalate complex, which eventually generates. $\mathrm{O}_{2}^{-}, \mathrm{O}_{2} \mathrm{H}$ and. $\mathrm{OH}$ radicals in the solution in presence of UV light.

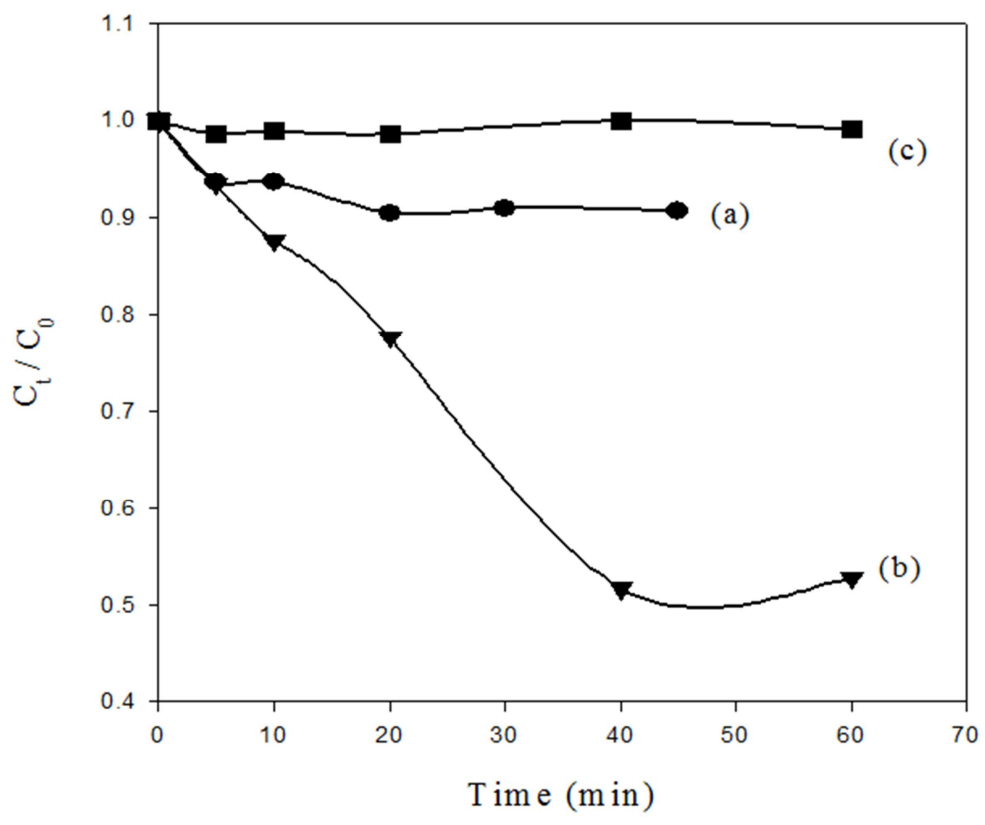

Figure 2. Photodegradation of $\mathrm{MB}\left(1.0 \times 10^{-5} \mathrm{M}\right)$ under different conditions (a) $0.5 \mathrm{~g} / \mathrm{L} \mathrm{Fe} \mathrm{O}_{3}+U \mathrm{~V}$-light; (b) $0.5 \mathrm{~g} / \mathrm{L}$ of $\mathrm{Fe}_{2} \mathrm{O}_{3}+U V$ light $+1.0 \times 10^{-3} \mathrm{M}$ oxalic acid \& (c) $0.5 \mathrm{~g} / \mathrm{L} \mathrm{Fe}_{2} \mathrm{O}_{3}+1.0 \times 10^{-3} \mathrm{M}$ oxalic acid.

\subsection{Effect of Initial Concentration of Oxalic Acid}

A series of experiments were performed to investigate the effect of the initial concentration of oxalic acid. To perform these experiments concentration of oxalic acid was varied from $0.1 \times 10^{-3} \mathrm{M}$ to $5.0 \times 10^{-3} \mathrm{M}$ in presence of a fixed concentration of MB $\left(1 \times 10^{-5} \mathrm{M}\right)$ and a fixed amount of $\mathrm{Fe}_{2} \mathrm{O}_{3}$ $(0.5 \mathrm{~g} / \mathrm{L})$ calcined at $400^{\circ} \mathrm{C}$ under UV-light irradiation (Figure 3).

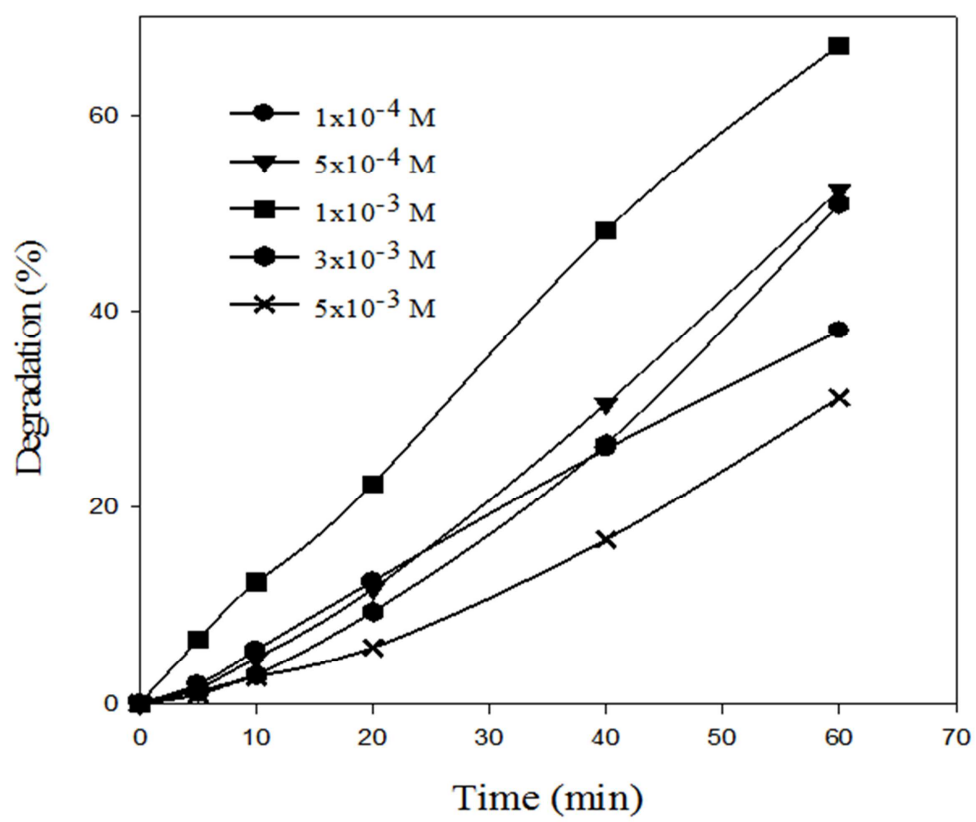

Figure 3. Percentage degradation of $M B$ as a function of time with the variation of concentration of oxalic acid. Where initial concentration of $M B=1.0 \times 10$ ${ }^{5} \mathrm{M}$ in $0.5 \mathrm{~g} / \mathrm{L} \mathrm{Fe}_{2} \mathrm{O}_{3}$ suspension, light source $=U \mathrm{~V}$ light.

It was observed that with the increase of concentration of oxalic acid degradation of MB increases to a maximum and then gradually decreases. Maximum degradation of MB was found to be $67 \%$ and the optimum oxalic acid concentration has been found to be $1.0 \times 10^{-3} \mathrm{M}$ (Figure 4). When the concentration of oxalic acid is greater than $0.18 \times 10^{-3} \mathrm{M}$, in the $\mathrm{Fe}_{2} \mathrm{O}_{3}$-oxalate system $\mathrm{Fe}^{3+}$ exits mainly as $\left[\mathrm{Fe}\left(\mathrm{C}_{2} \mathrm{O}_{4}\right)_{2}\right]^{-}$ and $\left[\mathrm{Fe}\left(\mathrm{C}_{2} \mathrm{O}_{4}\right)_{3}\right]^{3-}[19]$. Photolysis of these complexes is much more efficient than other $\mathrm{Fe}^{3+}$ species [24] and thus, production of oxidizing intermediates is also prominent. For this reason, presence of oxalic acid is expected to greatly enhance the photodegradation of MB. The present 
observation shows that photodegradation of $\mathrm{MB}$ has been enhanced when concentration of oxalic acid was increased from $0.1 \times 10^{-3} \mathrm{M}$ to $1.0 \times 10^{-3} \mathrm{M}$ suggesting the effective formation of complex ions $\left[\mathrm{Fe}\left(\mathrm{C}_{2} \mathrm{O}_{4}\right)_{2}\right]^{-}$and $\left[\mathrm{Fe}\left(\mathrm{C}_{2} \mathrm{O}_{4}\right)_{3}\right]^{3-}$.

$$
\mathrm{Fe}_{2} \mathrm{O}_{3}+3 \mathrm{H}_{2} \mathrm{C}_{2} \mathrm{O}_{4} \rightarrow\left[\mathrm{Fe}\left(\mathrm{C}_{2} \mathrm{O}_{4}\right)_{3}\right]^{3-}
$$

$$
\begin{aligned}
& {\left[\mathrm{Fe}\left(\mathrm{C}_{2} \mathrm{O}_{4}\right)_{3}\right]^{3-}+\mathrm{h} v \rightarrow\left[\mathrm{Fe}\left(\mathrm{C}_{2} \mathrm{O}_{4}\right)_{2}\right]^{2-}+.\left(\mathrm{C}_{2} \mathrm{O}_{4}\right)^{-}} \\
& \left(\mathrm{C}_{2} \mathrm{O}_{4}\right)^{-} \rightarrow \mathrm{CO}_{2}+.\left(\mathrm{CO}_{2}\right)^{-} \\
& \left(\mathrm{CO}_{2}\right)^{-}+\mathrm{O}_{2} \rightarrow \mathrm{CO}_{2}+. \mathrm{O}_{2}^{-} \\
& \mathrm{O}_{2}^{-}+\mathrm{H}^{+} \rightarrow . \mathrm{O}_{2} \mathrm{H}
\end{aligned}
$$

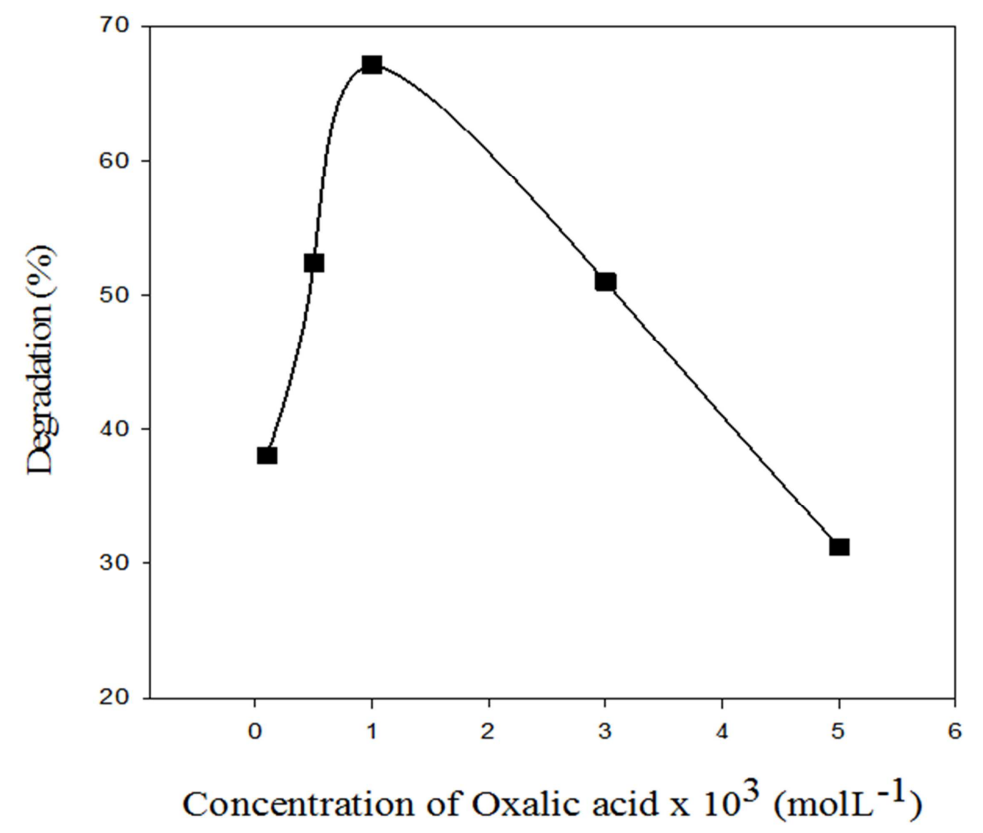

Figure 4. Percentage degradation of $M B$ as a function of oxalic acid concentration for 60 minutes under UV irradiation. Where, initial concentration of MB was $1.0 \times 10^{-5} \mathrm{M}$ in $0.5 \mathrm{~g} / \mathrm{L} \mathrm{Fe}_{2} \mathrm{O}_{3}$ suspension.

When oxalic acid concentration exceeds $1.0 \times 10^{-3} \mathrm{M}$ degradation of $\mathrm{MB}$ starts to decrease. The reason would be that the excess oxalic acid may compete with MB in two ways, firstly for the adsorption sites on ferric oxide surface and secondly, in the reaction generating. $\mathrm{OH}$ radicals $[23,24]$. That means oxalic acid itself can also be degraded by. $\mathrm{OH}$ radicals.

\subsection{Effect of Initial Concentration of $M B$}

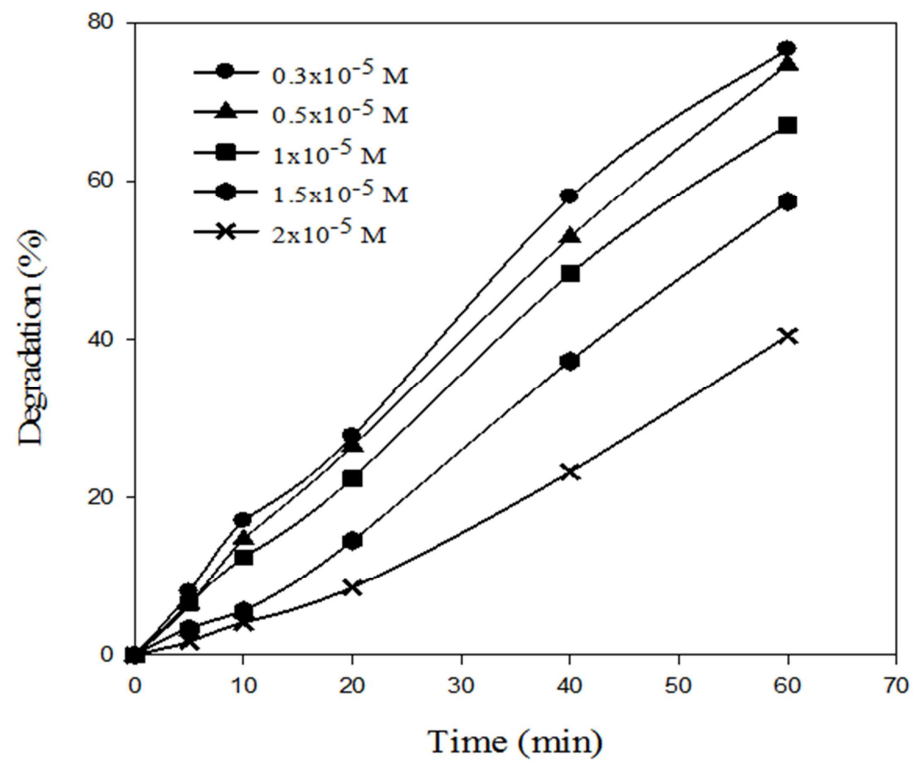

Figure 5. Percentage degradation of $M B$ as a function of time for different initial concentrations of $M B$. Where, initial concentration of oxalic acid $=1.0 \times 10^{-}$ ${ }^{3} \mathrm{M}$, amount of $\mathrm{Fe}_{2} \mathrm{O}_{3}=0.5 \mathrm{~g} / \mathrm{L}$ and light source $=$ UV light.

The effect of concentration of MB on its photodegradation was investigated by performing several experiments with 
different initial concentration of $\mathrm{MB}$ ranging from $0.3 \times 10^{-5}$ $\mathrm{M}$ to $2.0 \times 10^{-5} \mathrm{M}$ at a fixed concentration of oxalic acid (1.0 $\left.\times 10^{-3} \mathrm{M}\right)$ in $0.5 \mathrm{~g} / \mathrm{L}$ of $\mathrm{Fe}_{2} \mathrm{O}_{3}$ calcined at $400^{\circ} \mathrm{C}$ under $\mathrm{UV}$ light illumination. It was observed that, with the increase of initial concentration of $\mathrm{MB}$, degradation gradually decreases (Figure 6). Since, a definite amount of Fe(III) catalyst produces definite amount of superoxides and hydroperoxyl radicals, these radicals can only attack a proportional amount of MB species. Accordingly, as the concentration of $\mathrm{MB}$ increases the number of available MB species to be attacked by the radicals also increases. Hence the percentage degradation falls. Foad Kazemi et al. found the same pattern while studying photodegradation of methylene blue with a titanium dioxide/polyacrylamide photocatalyst under sunlight [26].

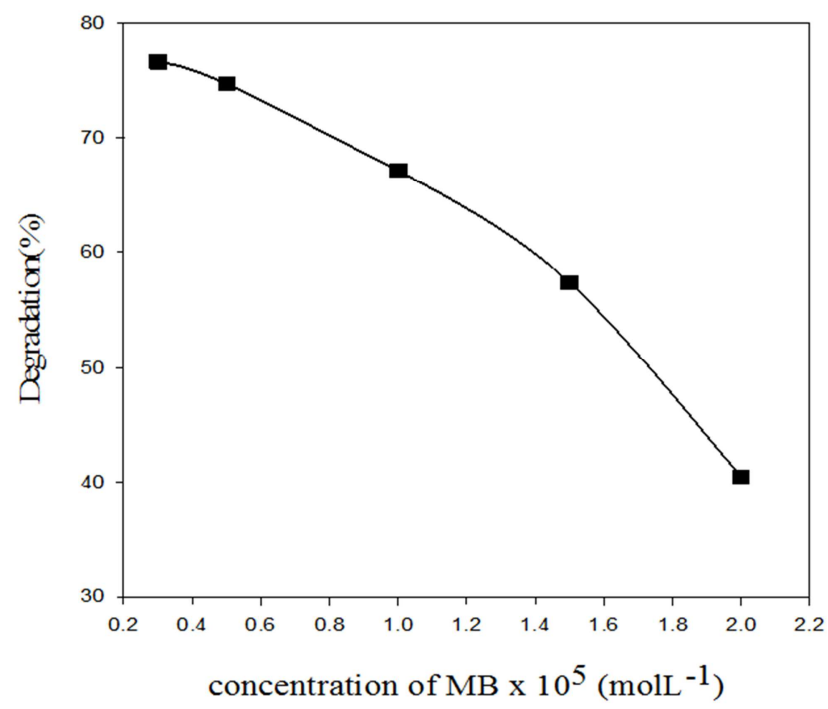

Figure 6. Percentage degradation of $M B$ as a function of initial concentration of $M B$. Initial concentration of oxalic acid $=1.0 \times 10^{-3} \mathrm{M}$, amount of $\mathrm{Fe}_{2} \mathrm{O}_{3}=0.5 \mathrm{~g} / \mathrm{L}$ and light source $=U \mathrm{~V}$ light.

\subsection{Effect of Calcination Temperature of $\mathrm{Fe}_{2} \mathrm{O}_{3}$}

Several experiments were carried out to investigate the effect of different calcined temperatures of $\mathrm{Fe}_{2} \mathrm{O}_{3}(0.5 \mathrm{~g} / \mathrm{L})$ with $1.0 \times 10^{-3} \mathrm{M}$ of oxalic acid and $3.0 \times 10^{-6} \mathrm{M}$ of MB (Figure 7). Photodegradation increases with increasing calcined temperatures of $\mathrm{Fe}_{2} \mathrm{O}_{3}$ (Figure 8) due to the increase in dissolution of $\mathrm{Fe}^{3+}$ in the suspension that favors the generation of. $\mathrm{OH}$ via following reactions:

$$
\begin{aligned}
& \mathrm{O}_{2}^{-}+\mathrm{Fe}^{3+} \rightarrow \mathrm{Fe}^{2+}+\mathrm{O}_{2} \\
& \mathrm{O}_{2}{ }^{-} \cdot \mathrm{O}_{2} \mathrm{H}+\mathrm{nH}^{+}+\mathrm{Fe}^{2+} \rightarrow \mathrm{Fe}^{3+}+\mathrm{H}_{2} \mathrm{O}_{2} \\
& \mathrm{Fe}^{2+}+\mathrm{H}_{2} \mathrm{O}_{2} \rightarrow \mathrm{Fe}^{3+}+\mathrm{OH}^{-}+. \mathrm{OH}
\end{aligned}
$$

The experimental results of Abdullah et al. also showed that with increasing calcination temperature the photodegradation efficiency of a catalyst increases [27].

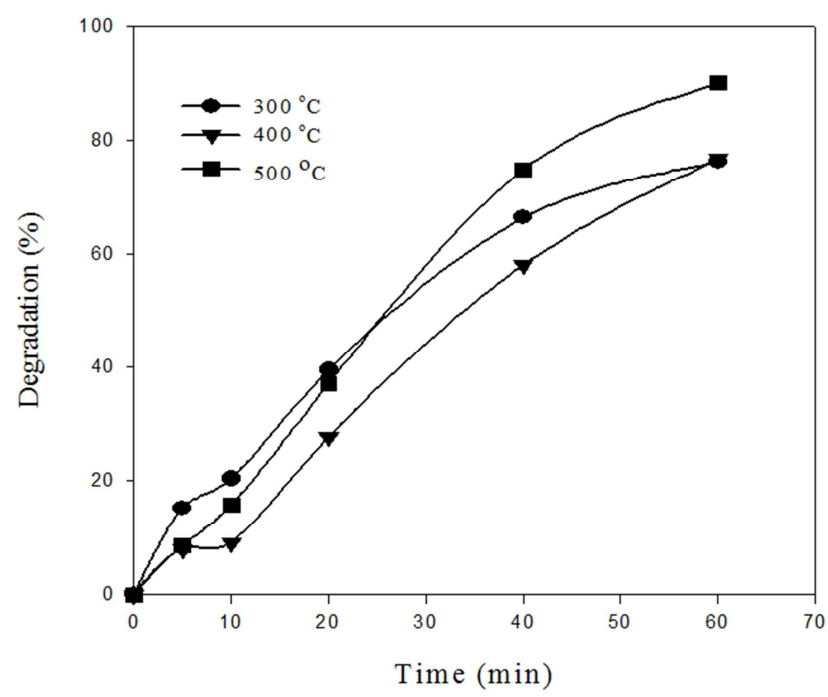

Figure 7. Percentage degradation of $\mathrm{MB}$ in a suspension of $0.5 \mathrm{~g} / \mathrm{L} \mathrm{Fe}_{2} \mathrm{O}_{3}$ as a function of time. Where, initial concentration of oxalic acid $=1.0 \times 10^{-3} \mathrm{M}$, Initial concentration of $M B=3.0 \times 10^{-6} \mathrm{M}$ and light source $=U \mathrm{~V}$ light.

In addition to this, increase in temperature may also enhance the process of complexation between $\mathrm{Fe}(\mathrm{III})$ and oxalic acid. Maximum degradation of $\mathrm{MB}$ was found to be $90 \%$ with $\mathrm{Fe}_{2} \mathrm{O}_{3}$ calcined at $500^{\circ} \mathrm{C}$.

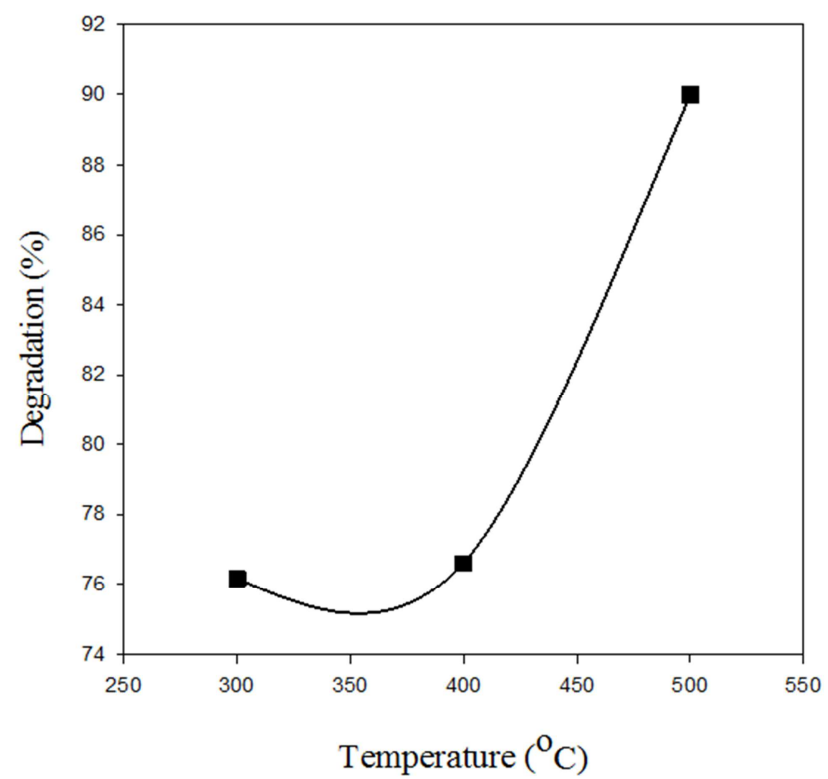

Figure 8. Percentage degradation of $\mathrm{MB}$ in a suspension of $0.5 \mathrm{~g} / \mathrm{L} \mathrm{Fe}_{2} \mathrm{O}_{3}$ as a function of calcined temperatures of $\mathrm{Fe}_{2} \mathrm{O}_{3}$. Where, initial concentration of oxalic acid $=1.0 \times 10^{-3} \mathrm{M}$, initial concentration of $\mathrm{MB}=3.0 \times 10^{-6} \mathrm{M}$ and light source $=$ UV light.

\section{Conclusion}

The photodegradation behavior of methylene blue was investigated using calcined commercial iron oxides in oxalate solution, illuminating with UV radiation. From the investigations it can be concluded that, the combination of iron oxide, oxalic acid and UV light illumination is necessary for the photodegradation of MB. For $0.5 \mathrm{~g} / \mathrm{L} \mathrm{Fe}_{2} \mathrm{O}_{3} 30$ minutes were required to reach adsorption equilibrium. 
Under experimental conditions $\left(\mathrm{MB}\right.$ concentration $=1.0 \times 10^{-5}$ $\mathrm{M}$ and iron oxide $0.5 \mathrm{~g} / \mathrm{L}$ ) the optimum oxalic acid concentration is $1.0 \times 10^{-3} \mathrm{M}$. Under experimental conditions (oxalic acid concentration $=1.0 \times 10^{-3} \mathrm{M}$ and iron oxide 0.5 $\mathrm{g} / \mathrm{L}$ ) with the increase of MB concentration photodegradation decreases. $\mathrm{Fe}_{2} \mathrm{O}_{3}$ calcined at higher temperature shows better photocatalytic activity. $90 \%$ of the methylene blue can be degraded when all the optimum conditions are maintained. Hence we can conclude that $\mathrm{Fe}_{2} \mathrm{O}_{3}$ in combination with oxalic acid in presence of UV light can be used as an efficient wastewater treatment procedure.

\section{References}

[1] H. Park, and W. Choi,. J. Photochem. Photobiol. A: Chem., 2003, 159, 241.

[2] J. R. Easton, The dye marker's view. Oxford: Society of Dyers and Colourists, The Alden Press, 1995, p. 9-21.

[3] H. Selcuk. "Decolorization and detoxification of textile wastewater by ozonation and coagulation processes". Dyes and Pigments. 2005, 64(3), 217-222.

[4] J. Kiwi, C. Pulgarin, and P. Peringer. "Effect of Fenton and photo-Fenton reactions on the degradation and biodegradability of 2 and 4-nitrophenols in water treatment". App. Catal. B: Environ. 1994, 3, 335.

[5] D. Oussi, A. Mokrini and S. Esplugas. "Removal of aromatic compounds using UV/ $\mathrm{H}_{2} \mathrm{O}_{2}$ ". Trends Photochem. Photobiol. 1997, 1, 77-83.

[6] F. Herrera, J. Kiwi, A. Lopez and V. Nadtachenk. "Photochemical decoloration of Remazol Brilliant blue and Uniblue $\mathrm{A}$ in the presence of $\mathrm{Fe}(\mathrm{III})$ and $\mathrm{H}_{2} \mathrm{O}_{2}$." Environ. Sci Technol. 1999, 33, 3145.

[7] D. Georgiou, P. Melidis, A. Aivasidis and K. Gimouhopoulos. "Degradation of azo-reactive dyes by ultraviolet radiation in the presence of hydrogen peroxide" Dyes and Pigments. 2002, $52,69-78$

[8] O. Prieto, J. Fermoso, Y. Nuñez, J. L. del Valle. and R. Irusta, Sol. Energy. 2005, 79, 376.

[9] H. Chun, and Y. Wang. Chemosphere.1999.39, 2107.

[10] M. S. T. Gonçalves, E. M. S. Pinto, P. Nkeonye and A. M. F. Oliveira-Campos. "Degradation of C. I. Reactive. Orange 4 and its Simulated Dyebath Wastewater by Heterogeneous Photocatalysis" Dyes and Pigments. 2005, 64, 135-139.

[11] J. K. Lelandand A. J. Brad. "Photochemistry of Colloidal. Semiconducting Iron Oxide Polymorphs" J. phys. chem. 1987, 91, 5076.
[12] C. Siffert and B. Sulzberger, Langmuir. 1991, 7, 1627-34.

[13] R. M. Cornelland U. Schwertmann. "The Iron Oxides: Structure, Properties, Reactions, Occurences and Uses, $\left(2^{\text {nd }}\right.$ ed.)"Wiley-VCH, Weinheim. 2003.

[14] T. Kayashimaand T. Katayama. "Oxalic acid is available as a natural antioxidant in some systems." Biochim. Biophys. Acta: Gen. Subj., 2002, 1573(1), 1-3.

[15] H. Kušić, N. Koprivanac, A. L. Božić and S. Selanec, J. Hazard. Mater. B., 2006, 136, 632-644.

[16] X. L. Hao, M. H. Zhou. and L. C. Lei, J. Hazard. Mater. B., 2007, 141(3), 475-82.

[17] G. Sposito. "The Surface Chemistry of Soils." Oxford University Press, Oxford, UK, 1989.

[18] V. Nadtochenkoand J. Kiwi. "J. Chem. Soc., Faraday Trans., 1997, 93, 2373-78.

[19] M. E. Balmer and B. Sulzberger. "Atrazine Degradation in Irradiated Iron/Oxalate Systems: Effects of $\mathrm{pH}$ and Oxalate" Environ. Sci. Technol., 1999, 33(14), 2418-24.

[20] P. Mazellier, and B. Sulzberger. "Diuron degradation in irradiated, heterogeneous iron/oxalate systems: the ratedetermining step" Environ. Sci. Technol. 2001, 35(16), 331420 .

[21] J. Lei, C. Liu, F. Li, X. Li, S. Zhou, X. Liu, G. Ming andQ. Wu, J. Hazard. Mater. B., 2006, 137, 1016.

[22] F. B. Li, X. Z. Li, X. M. Li, T. X. Liu and J. Dong. "Heterogeneous photodegradation of bisphenol A with iron oxides and oxalate in aqueous solution." J. Colloid Interface Sci. 2007, 311(2), 481-90.

[23] X. Wang, C. Liu, X. Li, F. Li and S. Zhou, J. Hazard. Materials. 2008, 153, 426.

[24] F. Gulshan, S. Yanagida, Y. Kameshima, T. Isobe, A. Nakajima and K. Okada. "Various factors affecting photodecomposition of methylene blue by iron-oxides in an oxalate solution." Water research. 2010, 44(9), 2876-84.

[25] S. D. Abkenar, M. Khoobi, R. Tarasi, M. Hosseini, A. Shafiee and M. R. Ganjali. "Fast removal of methylene blue from aqueous solution using magnetic-modified $\mathrm{Fe}_{3} \mathrm{O}_{4}$ nanoparticles.” J. Environ. Eng. 2015, 141(1).

[26] F. Kazemi, Z. Mohamadnia, B. Kaboudin and Z. Karimi. "Photodegradation of methylene blue with a titanium dioxide/polyacrylamide photocatalyst under sunlight." J. Appl. Polym. Sci. 2016, 133(19), 43386.

[27] N. S. A. Abdullah, S. Soaib and J. Krishnan. "Effect of calcination temperature on $\mathrm{ZnO} / \mathrm{TIO}_{2}$ composite in photocatalytic treatment of phenol under visible light." Malaysian Journal of Analytical Sciences, 2017 Vol 21(1), 173-181. 